\title{
Laboratory-reared Zoeae and Megalopae of Zuwai Crab from the Sea of Japan
}

\author{
Hiroshi MotoH* \\ (Received September 25, 1973)
}

\begin{abstract}
In order to provide a detailed description of all the larval stages of Chionoecetes opilio, and determine a basis for future descriptions of all the species of the genus Chionoecetes, an ovigerous female crab was caught by the Danish seine fishery, on February 16, 1971. Hatching occurred on March 2 to 5. There are two zoeal stages and one megalopa in the larval development of $C h$. opilio. The first zoea is 4.8 to $5.4 \mathrm{~mm}$ in length, 3.3 to $3.9 \mathrm{~mm}$ in width, and the second is 6.2 to $7.1 \mathrm{~mm}$ in length and 3.6 to $3.9 \mathrm{~mm}$ in width. The endopodite of the first maxilliped has five segments with a spinal arrangement from proximal to distal of $3,2,1,2,5$, and the second has three segments with a spinal arrangement $1,1,5$. The megalopa is 2.9 to $3.3 \mathrm{~mm}$ in carapace length and $1.9 \mathrm{~mm}$ carapace width. Seven heavy processes are on the carapace: three rostral, a pair of anterior gastric lateral, and a pair of cardiac dorso-lateral. The fourth walking leg has no conspicuous hair projecting from the tip of the dactylopodite.
\end{abstract}

Two species of crabs of the genus Chionoecetes, Ch. opilio (O. FABricius) and $C h$. iaponicus Rathbun, occur on the Sea of Japan. The former species (Zuwai Crab in Japanese name) is caught by the Danish seine fishery from the sea bottom at the depth from 200 to 350 meters and the latter (Beni-zuwai $\mathrm{Crab}$ ) captured by the basket fishery ("Kani-kago", a kind of crab trap) from a much deeper bottom, 700 to 1,500 meters.

Chionoecetes opilio is the most important commercial species in the Tōhoku, Hokuriku, and San-in Districts of Japan faced on the Sea of Japan, annually producing about 12,000 tons of the shell crab with a value 3,200 million yen (12 million dollars, approximately) to the fishermen. The larval development of this species has been studied by several authors. AIKAWA ${ }^{1,2,3)}$ described the prezoea or first zoea not fully developed. KURATA ${ }^{4)}$ reported the first and second zoeae, and megalopa from the plankton obtained from Hokkaido and the adjacent waters. $\mathrm{KoN}^{5)}$ noted a prezoea stage from the middle Sea of Japan, and KuwATANi et al. ${ }^{\text {) }}$ described the prezoea (as protozoea) and the first zoea based on laboratory-reared larvae from Hokkaido.

The object of this paper is to provide a detailed description of all the larval stages of Ch. opilio, and a basis and method for future descriptions of zoeae of all the species of the genus Chionoecetes.

\section{Materials and Methods}

On February 16, 1971, an ovigerous female crab, caught by the Danish seine fishery

* Mar. Cult. Stat. Ishikawa Pref., Notojima, Ishikawa, Japan.（本尾 洋：石川塄增殖試験場） 
at the depth about 250 meters, off Noto Peninsula, the Sea of Japan, was placed in the wooden tank of a fishing boat, "Ensei-maru". About twenty hours later, the crab was transported to the laboratory and placed in a plastic tank of 500 liters capacity. The sea water was maintained at about $5^{\circ} \mathrm{C}$ by a refrigerator. An air pump is used to circulate the sea water in the tank. Sea water used was obtained from Nanao Bay in front of the Marine Culture Station of Ishikawa Prefecture and pumped to the laboratory and filtered by $60 \mu$ nylon meshes and stocked in the dark cooling room. Specific gravity of this water varied from 1.022 to $1.025(\sigma 15)$ during the period from February to May, due to the location of the aquarium intake which was influenced by rains.

Hatching occurred on March 2 to 5, 1971. By using a strong light and a largebore pipette, 200 photopositive zoeae were collected and distributed equally in 10 plastic $500 \mathrm{~m} /$ finger bowls. Daily or every other day the larvae were transferred into clean finger bowls with a new supply of filtered water, and then recently-hatched nauplii of the brine shrimp, Artemia salina were provided. Temperature fluctuations of the sea water during examinations are from $7.2^{\circ} \mathrm{C}$ to $13.0^{\circ} \mathrm{C}$. Heavy mortality was found during the stages of the second zoea and megalopa larvae.

\section{Description of Larvae}

All larvae hatched as prezoeal stage and they molted to the first zoea in about one hour. There are two zoeal and one megalopa stages in the larval development of $C h$. opilio.

First zoea The cephalothorax has four spines: a dorsal spine and a rostral spine approximately equal in length and a pair of lateral spines (Fig. 1; A, B). The eyes are not stalked. The length of the larva from the tip of rostral to tip of dorsal spine is 4.8 to $5.4 \mathrm{~mm}$, and the width including both lateral spines is 3.3 to $3.6 \mathrm{~mm}$. The distance between outer margines of eyes is 0.9 to $1.0 \mathrm{~mm}$. The abdomen consists of five segments and the telson, which is bifurcate. Each furca of the telson bears three setae on the inner side and a small spine each on the lateral and the ventral side, respectively. The posterolateral margins of $3 \mathrm{rd}$, 4th and 5th abdominal segments terminate as a pair of long lateral spines. The spines of 3 rd and 4 th segments are prolonged beyond the posterior margin of the following segments. The 2 nd and 3 rd segments bear a pair of lateral knobs or hooks (Fig. 1, J). The antennule bears three terminal processes: two broad flat aesthetes and a smaller seta (Fig. 1, C). The antenna is almost as long as the rostral spine (Fig. 1, A, B), and its peduncle tapers to a point with several rows of setules (Fig. 1, D). The exopodite has three setae, $1: 1.7$ to $2.3: 2.7$ to 3.8 in proportion of their length. The mandible is small with an irregular cutting edge (Fig. 1, F). The endopodite of the maxillule bears six spines of equal length that are arranged in pair, and one more spine is present at the base of the endopodite which later becomes an apparently separate 
segment (Fig. 1, F). The basipodite and coxopodite have six or seven setules, respectively (Fig. 1, F). The scaphognathite of the maxilla has twelve to fifteen (mainly twelve or thirteen) long soft plumose hairs including two or three thick ones, and the bifurcated

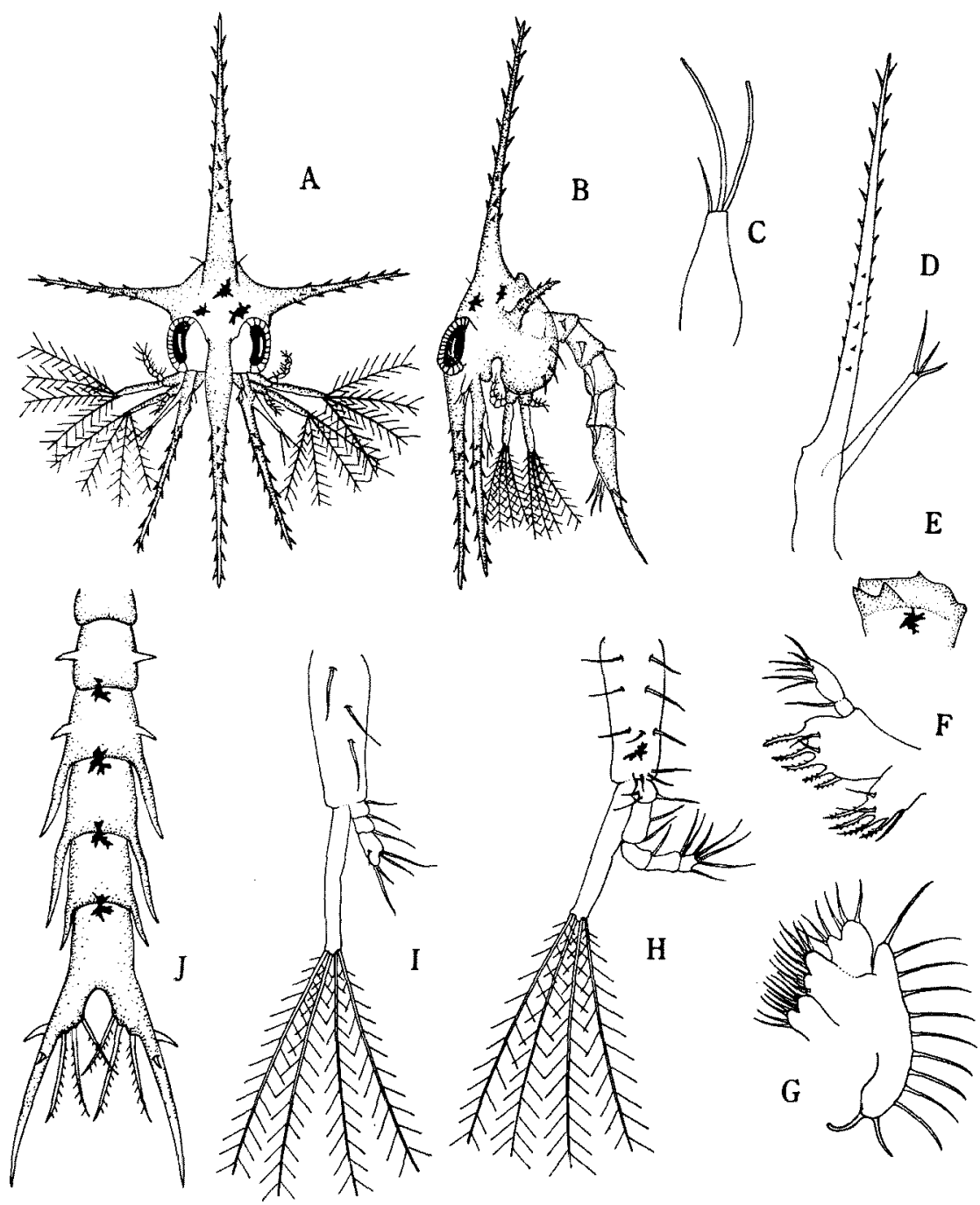

Fig. 1. Chionoecetes opilio (O. FAbRICIUS). First zoea. A, dorsal view; B, lateral view; C, antennule; $D$, antenna; $E$, mandible; $F$, maxillule; $G$, maxilla; $H$, first maxilliped; $I$, second maxilliped; J, abdomen in ventral view. A, B, $\times 30 ; \mathrm{C}, \mathrm{E}, \mathrm{F}, \mathrm{G}, \times 150 ; \mathrm{D}, \mathrm{H}$, $\mathrm{I}, \times 75 ; \mathrm{J}, \times 60$.

endopodite bears three spines on each lobe. The basipodite and coxopodite are also bifurcated and have the spinal arrangement of 5 or $4-5$ or 4 , and 44 , respectively (Fig. $1, \mathrm{G})$. The endopodite of the first maxilliped has five segments with a spinal arrange- 
ment of 3,2,1,2,5, from proximal to distal. Four natatory or swimming hairs are present on the distal end of the exopodite (Fig. 1, H). The second maxilliped also has four natatory hairs and a 1, 1, 5 spinal arrangement on the three segments of the endopodite. One of five spines on the distal is very minute (Fig. 1, I).

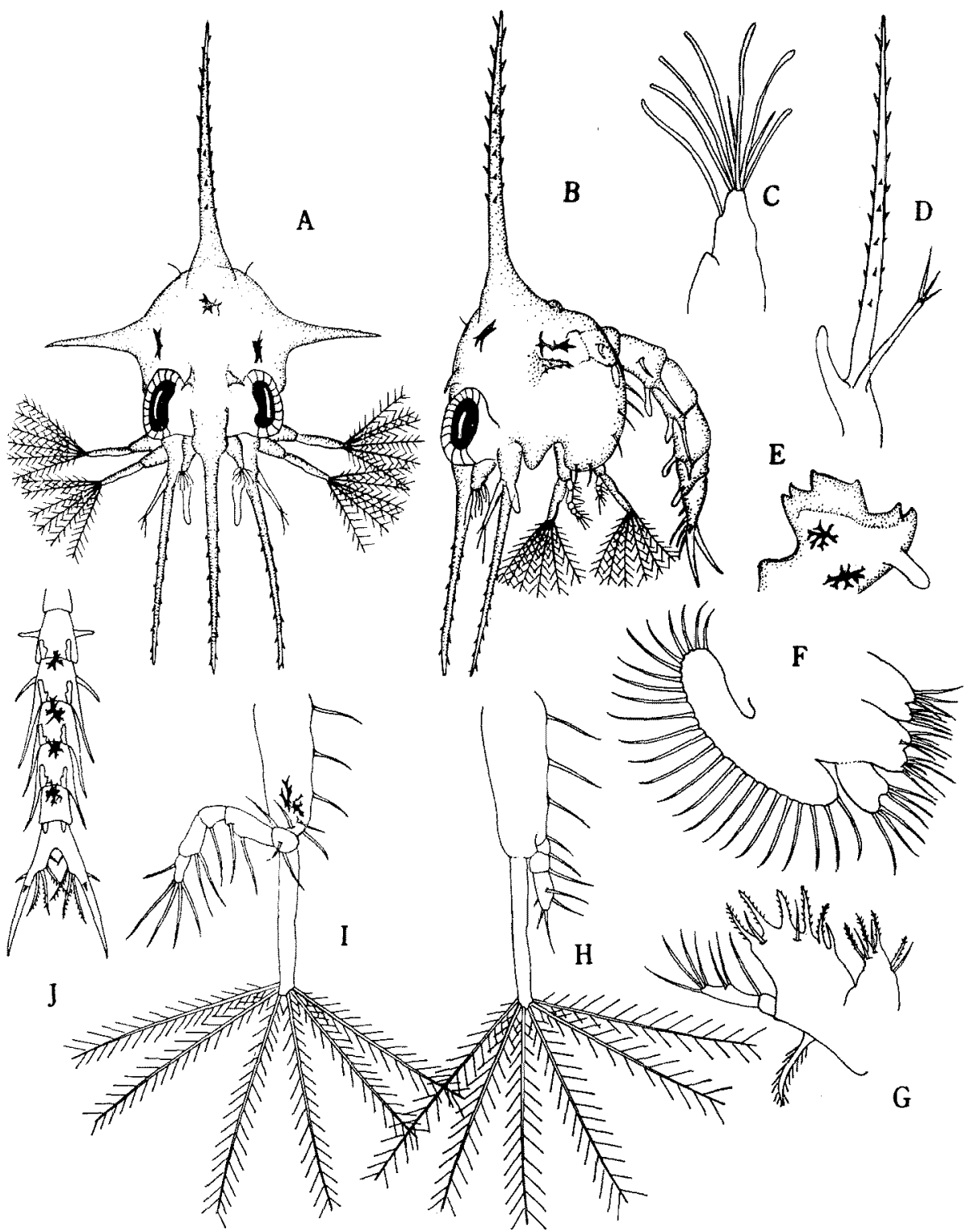

Fig. 2. Chionoecetes opilio (O. FABRICrus). Second zoea. A, dorsal view; B, lateral view; $\mathrm{C}$, antennule; D, antenna; E, mandible; F, maxilla; G, maxillule; $\mathrm{H}$, second maxilliped; I, first maxilliped; J, abdomen in ventral view A, B, J, $\times 30 ; C, D, \times 60 ; \mathrm{E}, \mathrm{F}, \mathrm{G}, \times 150$; $\mathrm{H}, \mathrm{I}, \times 75$. 
Second zoea The length of the larva from tip of rostral to tip of dorsal spine is $6.2-7.1 \mathrm{~mm}$. The width including both lateral spines is $3.6-3.9 \mathrm{~mm}$. The distance between outer margins of eyes is $1.3-1.5 \mathrm{~mm}$. The second zoea appears with the eyes stalked (Fig. 2, A, B). Aesthetes on the antennule are increased to nine and in two tiers: one in the first tier, and eight in the terminal tier which are six large and two small sensory flagella (Fig. 2, C). A club on the antenna represents the developing endopodite (Fig. 2, D). The mandible has an unsegmented palp (Fig. 2, E). The coxopodite and basipodite of the maxillule have six to eight and eight to nine spines, respectively. An additional spine or plumose hair is located on the protopodite near the base of the endopodite. The basipodite and coxopodite of the maxilla bear six and four spines on each lobe (Fig. 2, F). The scaphognathite of the maxilla has 20 to 23 (mainly 22 or 23) long soft plumose hairs including 2 or 3 thick ones (Fig. 2, F). The endopodite of the maxillule now consists of two segments with a spinal arrangement of 1, 6 (Fig. 2, G). Each maxilliped bears six plumose swimming hairs on the exopodite (Fig. 2, H, I). The inner margin of each prong of the furca of the telson bears one additional spine without setule (Fig. 2, J).

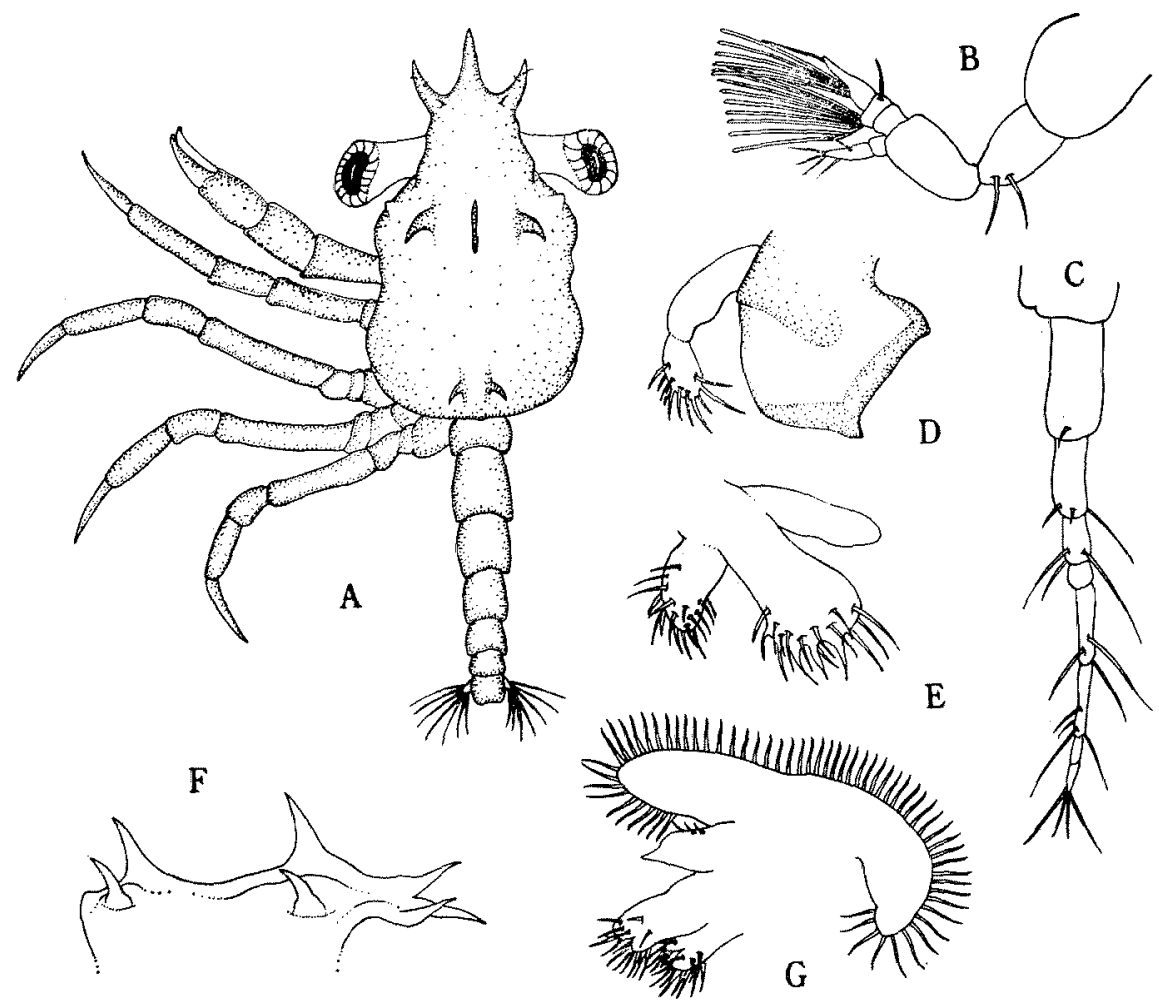

Fig. 3. Chionoecetes opilio (O. FABRIcrus). Megalopa. A, dorsal view; B, antennule; C, antenna; D, mandible; $E$, maxillule; $F$, lateral view of carapace; $G$, maxilla. $A, F, \times 30$; $\mathrm{B}, \mathrm{C}, \times 75 ; \mathrm{D}, \mathrm{E}, \mathrm{G}, \times 150$. 
Megalopa The Ch. opilio megalopa is 2.9 to $3.3 \mathrm{~mm}$ in carapace length including rostral central process and $1.9 \mathrm{~mm}$ in carapace width. Seven heavy processes are on the carapace: three rostral processes, of which central one is longer than the lateral two, a pair of anterior gastric lateral processes, and a pair of cardiac dorso-lateral (Fig. 3, A, F). The eyes are stalked. Spines also project ventrally from the basi-ischiopodites of the cheliped and walking legs except for the fourth leg. The fourth walking leg has no conspicuous hair projecting from the tip of the dactylopodite (Fig. 4, L). The inflated peduncle of the antennule is followed by two segments (Fig. 3, B). The palp of the mandible is well developed and bears about 11 spines (Fig. 3, D). The endopodite of the maxillule has no spine (Fig. 3, E). The scaphognathite of the maxilla is much broader, with 60 to 62 soft plumose hairs (Fig. 3, G). Spines on the coxopodite have increased to eleven on one lobe of bifurcation and five on the other (Fig. 3, G). The basipodite has five spines on one lobe and eight on the other as usual (Fig. 3, G). The
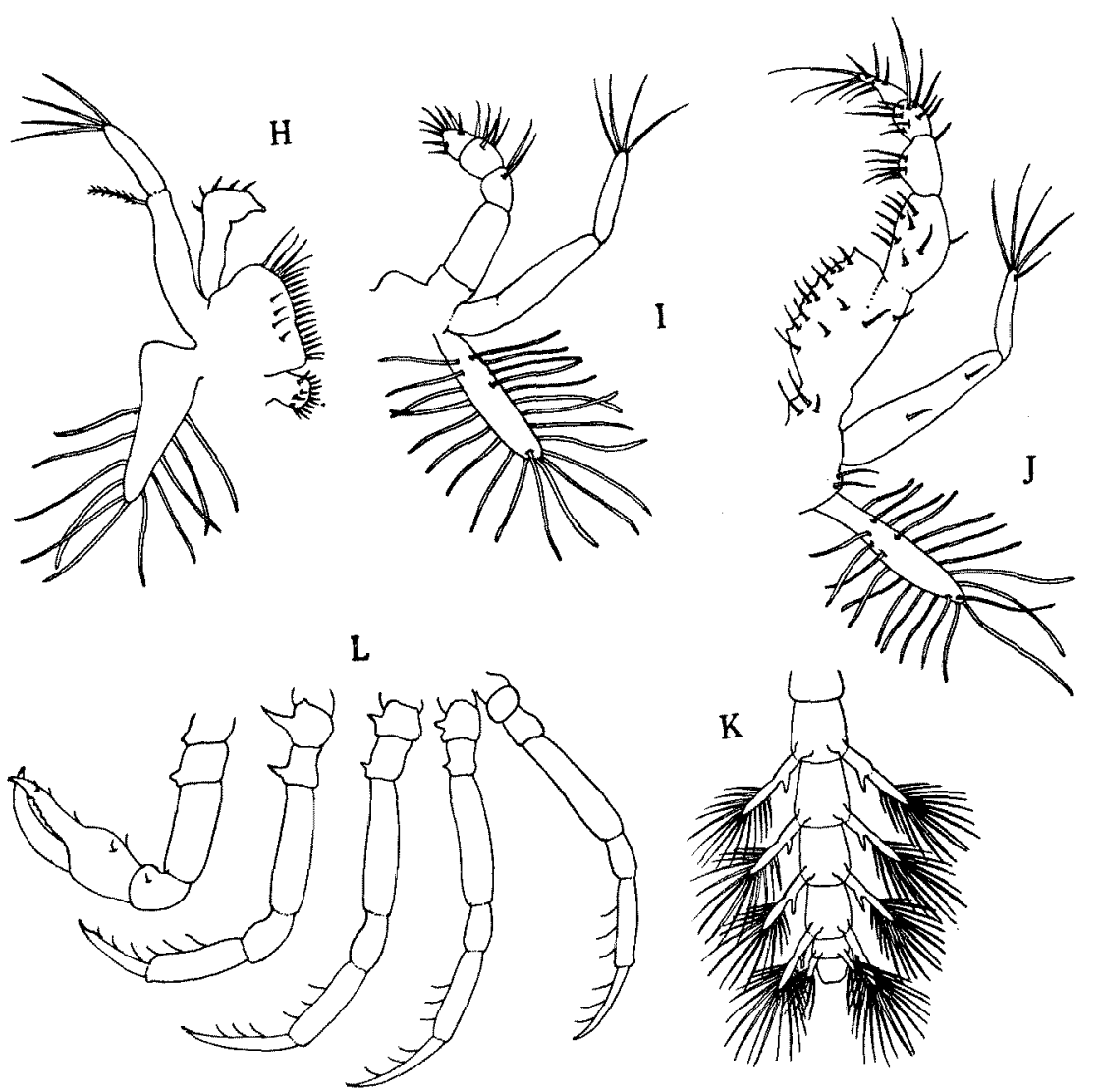

Fig. 4. Chionoecetes opilio (O. FABricius). Megalopa. H, first maxilliped; I, second maxilliped; $J$, third maxilliped; $K$, abdomen in ventral view; $L$, pereiopods 1 st to 5 th. $H, I$, $\mathrm{J}, \times 150 ; \mathrm{K}, \mathrm{L}, \times 30$. 
endopodite has only three spines on its basal portion. The first maxilliped has a well developed epipodite with eleven soft hairs (Fig. 4, H). The broad endopodite has five spines on the distal end, and numerous spines on the basal end. One plumose and four terminal hairs are present on the exopodite (Fig. 4, H). The endopodite of the second maxilliped has four segments with a spinal arrangement from proximal to distal of 0 , 2, 5 and 8, respectively. Four natatory hairs are still present on the terminal end of the exopodite (Fig. 4, I). A well developed epipodite is also present, with approximately 22 soft-plumose hairs (Fig. 4, I). The third maxilliped has developed tremendously at metamorphosis from the second zoea to the megalopa (Fig. 4, J). The endopodite has become quite massive and consists of four segments with numerous spines. The epipodite is well developed, with about 21 soft non-plumose hairs (Fig. 4, J). The abdomen consists of six segments and the telson (Fig. 4, K). Pleopods are present on segments 2nd to 5 th and bear about 16 long plumose hairs for locomotion. But slight variation is noticed in the number of the hairs on each segment. There are 7 plumose hairs on the uropods. Gills are present, and are probably functional.

\section{Discussion}

For the identification of brachyuran zoeae, AIKAWA ${ }^{11}$ proposed the following four characters (1) spine on the carapace, (2) character of the second antenna, (3) character of the telson, including its armature, and (4) grouping of chromatophores.

The characters given by the present author for the first and second zoeae of Chionoecetes opilio are as follows: all of the dorsal, ventral and lateral spines present; second antenna B-type of AIKAWA (a typical one with an exopodite about half or a little more than half as long as the peduncle); telson A-type of AIKAWA ${ }^{11}$ (the telson-fork is well developed, one to two thirds as long as the telson); chromatophores of reddish brown in color present in second, third, fourth and fifth abdominal segments, protopodite of the third maxilliped (and in second maxilliped, rarely), on the caparace and mandible.

In comparison with the characters given by AIKAWA and by authors, the first zoea of the present materials mainly agrees with the AikawA's, Kurata's and Kuwatani's except for the characters A, B, C, F, I, K and $L$ as shown in Table 1. AIKAwA's materials seem to be not fully developed according to KURATA ${ }^{4}$. KURATA's materials mainly depend on the plankton from Hokkaido, and KuWATANI's ovigerous crabs were caught off Hokkaido, the most northern Sea of Japan. While the specimen in the present investigation came from the middle Sea of Japan. For these reasons, it seems likely that the differences between these larvae may depend on the crabs in different habitats and localities. 
Table 1. Comparison of the characters of the first zoea of Chionoecetes opilio (O. FABRIcius). *, not given.

\begin{tabular}{|c|c|c|c|c|}
\hline Character & AIKAWA & Kurata & KUWATANI et al & Мотон \\
\hline A, Spines outer margin telson furca & 2 & 3 & 2 & 2 \\
\hline $\begin{array}{l}\text { B, Lateral knobs on abdominal } \\
\text { segment }\end{array}$ & $3 \mathrm{rd}$ & 2nd \& 3rd & 2nd \& 3 rd & 2 nd \& 3 rd \\
\hline C, Spines endopodite maxillule & $1-5$ & $1-6$ & $1-6$ & $1-6$ \\
\hline D, Spines basipodite maxillule & * & * & 7 & 7 \\
\hline E, Spines coxopodite maxillule & $*$ & * & 7 & 7 \\
\hline$\vec{F}$, Spines endopodite maxilla & $2-3$ & $3-3-1$ & $3-2-1$ & $3-3$ \\
\hline G, Spines basipodite maxilla & * & * & $5-5$ & 5 or $4-5$ or 4 \\
\hline$H$, Spines coxopodite maxilla & * & * & $4-4$ & $4-4$ \\
\hline I, Setae scaphognathite & $*$ & 16 & 13 & 12 or 13 \\
\hline $\begin{array}{l}\text { J, Spinal arrangement Ist } \\
\text { maxilliped's endopodite }\end{array}$ & $*$ & $*$ & $3-2-1-2-5$ & $3-2-1-2-5$ \\
\hline $\begin{array}{l}\text { K, Spinal arrangement Ist } \\
\text { maxilliped's protopodite }\end{array}$ & $*$ & * & $3-3-3-3$ & $2-2-3-3$ \\
\hline L, Spinal arrangement 2nd & $?-?-5$ & $1-1-5$ & $1-1-4$ & $1-1-5$ \\
\hline $\begin{array}{l}\text { M, Spinal arrangement } 2 \text { nd } \\
\text { maxilliped's protopodite }\end{array}$ & * & $*$ & $1-1-1-1$ & $1-1-1-1$ \\
\hline
\end{tabular}

\section{Acknowledgements}

The present author wishes to express his deepest appreciation to Dr. Hiroshi KuRATA, Nanseikai Regional Fisheries Research Laboratory, and Dr. Prof. Kikuya MAsHIKo, Faculty of Science, University of Kanazawa, for their valuable suggestions through this work and helpful criticism on the manuscript. Thanks are also hereby tendered to Mr. Tadanobu Eтo, the director of this station, and Mr. Tetsuo Minagawa and Mr. Fusao NaGATA of this station for their assistance during the course of this experiment.

\section{References}

1) H. Aikawa: Rec. Oceanogr. Works Japan, 2, 17-55 (1929).

2) H. AlKawa: Zool. Mag., 47, 217-227 (1935).

3) H. AikaWA: Rec. Oceanogr. Works Japan, 9, 87-162 (1937).

4) H. Kurata: Bull. Hokkaido Reg. Fish. Res. Lab., No. 27, 25-31 (1963).

5) T. Kon: This Bull., 33, 726-730 (1967)

6) H. Kuwatani, T. Wakur and T. Nakanish: Bull. Hokkaido Reg. Fish. Res. Lab., No. 37, 32-40 (1971). 